\title{
Clinical presentation and risk factors of increased scabies cases in the Western region of Saudi Arabia in 2016-2018
}

\author{
Mohammed Wasil A. Jastaniah, MD, Ziad Faisal K. Zimmo, MD, Mazen Waleed S. Bakallah, MD, \\ Mohannad Saeed M. Hantoush, MD, Mohammed Abdal-Aziz, MD.
}

\begin{abstract}
الأهداف : وصف الخصائص السريرية لنو ع الجرب الذي تفشى بمنطقة

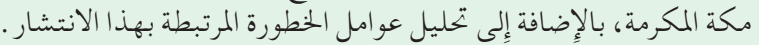
الطريقة : أجريت دراسة لاستقصاء الأوبئة خلال الفترة بين يونيو

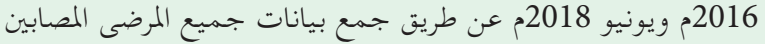

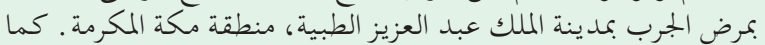

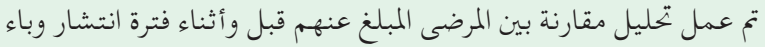
الجرب أبر.

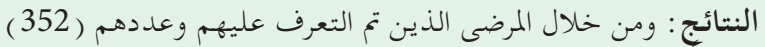

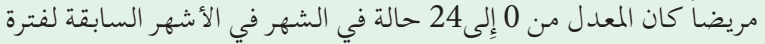

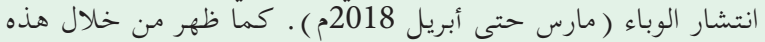

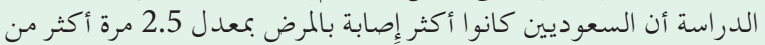

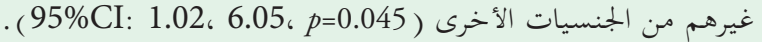

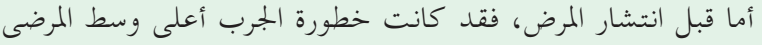
تحت إِجراء القسطرة (

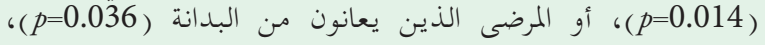

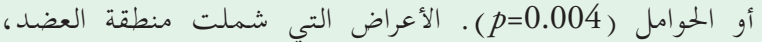
والإبطين 53.7\% بالمقابل (50\% بالمقابل 66.4\%

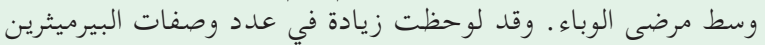

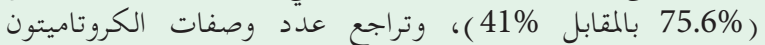

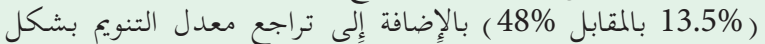
ملحوظ (3.8\% ) خلال فترة الوباء بالمقارنة مع (13.5\% (13.5\% ).

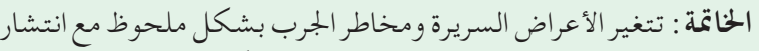
الوباء وتتيربنءا على ذلك طرق العر العلاج في المملكة العربية السعودية .
\end{abstract}

Objectives: To describe the clinical characteristics of scabies in the Makkah province and analyze risk factors associated with the outbreak.

Methods: A cross-sectional study was conducted between June 2016 and June 2018 by collecting the data of patients reported to have infestations at King Abdulaziz Medical City, Makkah, Saudi Arabia. A comparative analysis was conducted of patients reported before and during the outbreak of scabies.
Results: Of the 352 patients identified, the range of cases was 0-24 cases per month before the months of the outbreak (March to April 2018). However, the actual number of cases reported increased 2.8 times the expected maximum in April 2018. Saudi nationals were 2.5 times more affected than non-Saudi nationals during the outbreak period compared to before the outbreak (95\%CI: 1.02, 6.05, $p=0.045$ ). Symptoms involving upper arms, axillae $(53.7 \%$ versus $68.7 \%, p=0.048)$, and torso (50\% versus $66.4 \%, p=0.033$ ) were significantly under-represented among outbreak patients. The presence of additional comorbidities was reported more frequently in patients diagnosed with scabies before versus during the outbreak months $(25.8 \%$ versus $8.2 \%, p=0.014)$. Permethrin prescriptions increased $(75.6 \%$ versus $41 \%)$, crotamiton prescriptions decreased ( $13.5 \%$ versus $48 \%)$, and the hospitalization was lower (3.8\% versus $13.5 \%)$ during the outbreak.

Conclusion: The clinical presentation and risk factors of scabies change significantly with scabies outbreaks, and consequently so do the lines of treatment in Saudi Arabia. The present study highlights the importance of adopting strategies related to community infection control and prevention.

Saudi Med J 2019; Vol. 40 (8): 820-827 doi: 10.15537/smj.2019.8.24360

From the Department of Infection Prevention and Control (Jastaniah, Zimmo, Bakallah, Hantoush), King Abdullah International Medical Research Center; and from the Department of Infection Prevention and Control (Abdal-Aziz), King Abdulaziz Medical City, Ministry of National Guard Health Affairs, Jeddah, Kingdom of Saudi Arabia.

Received 25th January 2019. Accepted 26th June 2019.

Address correspondence and reprint request to: Dr. Mohammed Wasil A. Jastaniah, Department of Infection Prevention and Control, King Abdullah International Medical Research Center, King Abdulaziz Medical City, Ministry of National Guard Health Affairs, Jeddah, Kingdom of Saudi Arabia.E-mail: mohammedjastaniah@gmail.com ORCID ID: https://orcid.org/0000-0003-0669-5803 
S cabies, also known as the itch, is an infectious cutaneous disease caused by the itch mite Sarcoptes scabiei var hominis. Clinically, scabies is characterized by generalized, intense pruritis eruptions that worsen at night, classically at the finger webs, wrists, elbows, axilla, abdomen, external genitalia, buttocks, and on the breasts of women. ${ }^{1-3}$ The primary mode of transmission of the parasite is direct person-to-person physical contact with the infected case, and it is commonly considered a venereal disease. ${ }^{4,5}$ Less common modes of transmission include contact with contaminated fomites and clothing. The incubation period prior to the emergence of primary symptoms is 3 to 6 weeks. In the case of re-infection, the incubation period may be as short as 3 days. $^{4}$

Scabies accounts for a significant proportion of all dermatological conditions worldwide, with an estimated prevalence of 300 million cases yearly. ${ }^{4,6}$ Scabies poses a serious health problem, particularly in the developing world, and the burden of scabies and its complications in Pacific region countries is high., ${ }^{5,7}$ Scabies carries the risk of life-threatening complications such as secondary bacterial infection by group A streptococci, which may subsequently result in hazardous sequelae, namely glomerulonephritis and acute rheumatic fever. ${ }^{8}$ Poverty and overcrowding create fertile ground for the transmission of the disease. ${ }^{9}$ Studies of the prevalence of scabies suggest that epidemics and other documented fluctuations in the disease distribution are of multifactorial etiology, associated with variability in both social and environmental factors. ${ }^{7}$ Social factors that impact the distribution of scabies within populations include: overcrowding, age, gender, ethnicity, hygiene, developmental delay, malnutrition, immune status, and insufficient access to healthcare facilities. ${ }^{6}$ Furthermore, certain environmental factors promote the spread of scabies, for instance, seasonal and climatic changes.,9

In the Middle East region, very few detailed epidemiological studies about scabies epidemiology have been conducted, especially in the Kingdom of Saudi Arabia. A cross-sectional study in Al Hassa with 1,337 children participants in Saudi Arabian schools selected from rural and urban areas, revealed a higher distribution of this dermatological disease in rural primary school children. ${ }^{10}$ In 2018, a scabies outbreak occurred in Makkah city. ${ }^{11}$ Nearby health institutions

Disclosure. Authors have no conflict of interests, and the work was not supported or funded by any drug company. experienced a substantial increase in the number of reported scabies cases, which implied a probable association with the outbreak in Makkah city.

The aim of this single-center study is to describe the clinical characteristics and pattern of scabies in Makkah province, before and throughout the Makkah outbreak, to analyze the risk factors associated with the sudden increase in the number of reported cases to aid the identification of future preventive strategies.

Methods. A single-center, cross-sectional study at King Abdulaziz Medical City (KAMC), Jeddah, Saudi Arabia (a hospital with a capacity of 751 beds) and its primary healthcare centers; 1) King Faisal Residential City-Al Eskan, Jeddah, 2) King Khaled Residential City, Al Eskan, Taif, 3) Al Sharai in Makkah, 4) specialty clinics, 5) the Bahra Center, and 6) Um El Salam Center, Western Region (Makkah province) conducted a study between June 2016 and June 2018.

All patients with clinically definite scabies reported during this period were included in the study. The diagnosis was clinically-based and was carried out based on the presence of typical skin manifestations, the discovery of scabies mites, or dermatologist's consultation, as well as a positive response to anti-scabies treatment. Patients with other infectious dermatological diseases, or those who were prescribed anti-scabies medications for indications other than scabies, were excluded from the study.

Data of patients were collected retrospectively. Consecutive sampling was used in this study by extracting data from patients' electronic medical records from the studied center and its subsidiary primary healthcare centers. Patients' diagnoses and medications were searched to extract clinically definite scabies patients from the reviewed records. The variables extracted included clinical manifestations, risk factors, type of treatment received, comorbidities, and demographics. Risk factors included: history of an affected family member, contact with an affected school/work colleague, poor personal hygiene, low immune status due to disease or medication exposure, bedridden, prediagnosed venereal disease, dementia, catheterization, obesity, pregnancy, pre-existing dermatological disease/ condition, malnutrition, and stroke. These were analyzed both as a group of 'additional risk factors' and individually.

Extracted data were then analyzed by using the Statistical Package for Social Sciences, version 25 (IBM Corp., Armonk, NY, USA). Descriptive statistics (frequency, mean, and standard deviation) were calculated for all variables. Chi-square test and 
independent t-test were used to compare categorical and continuous variables between 2 groups. Fisher's exact test was used instead of Chi-square test when the expected value was $<5$ in more than $20 \%$ of the cells. Univariate logistic regression was used to estimate the odds ratio (OR) and 95\% confidence interval (CI) associated with different risk factors. Time series analysis was used to predict the number of patients during the period between March 2018 and June 2018. Significant test results were quoted as 2-tailed probabilities and judged at the $5 \%$ level. A comparative analysis was conducted between the patients recruited at 2 points in time: those reported between June 2016 and February 2018, as well as those reported between March 2018 to June 2018 (before and during the Makkah outbreak months, respectively). Subgroup analysis of the peak outbreak months compared with all other time points was also conducted.

Institutional review board approval was obtained from King Abdullah International Medical Research
Center, Jeddah, Saudi Arabia prior to commencing the data collection. Every patient file was labeled with a security number to maintain patient confidentiality at all times. Data collection sheets and excel sheets were locked and censored, with access limited to the investigators only. The study was conducted according to the principles of the Helsinki Declaration.

Results. During the period from June 2016 to June 2018, 352 patients were diagnosed with scabies and reported to KAMC and its primary healthcare centers. As depicted in Figure 1, the time series analysis showed that the number of scabies cases reported from June 2016 to February 2018 ranged from 0 to 24 cases per month. Thus, the mean expected number of cases in March, April, May, and June 2018 was 11 (0-24) cases per month. Accordingly, the expected number of cases during March 2018 was 10 cases and April 2018 was 6 cases. However, the actual number of cases reported in April 2018 was 2.8 times the expected maximum (the

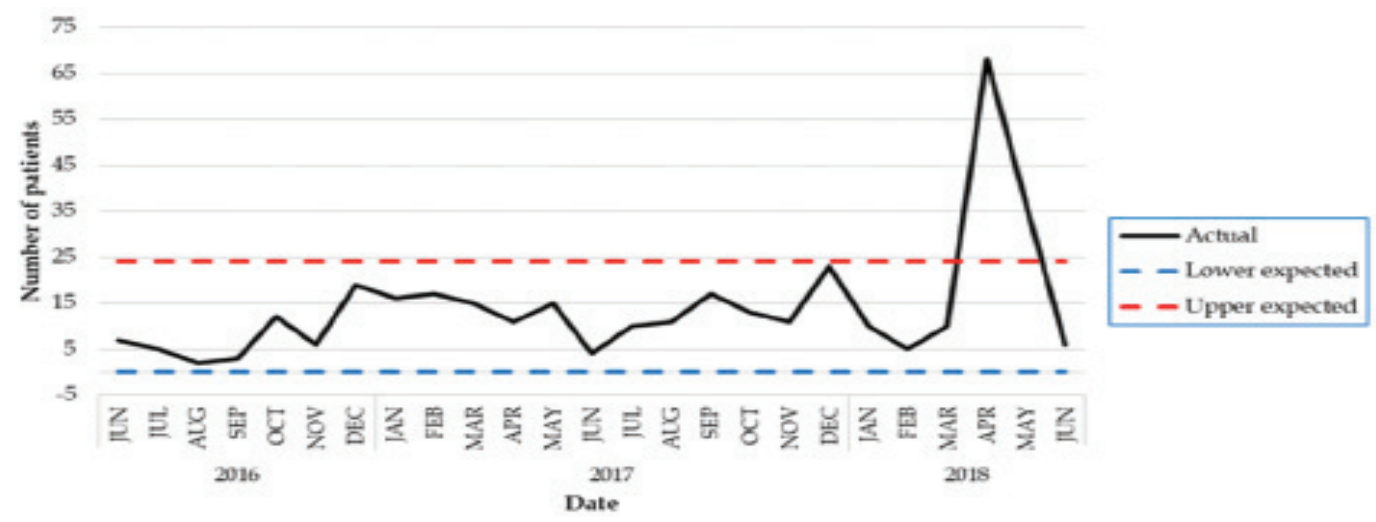

Figure 1 - The change in number of scabies cases admitted to King Abdulaziz Medical City, Makkah, Saudi Arabia - western region and its primary healthcare clinics between June 2016 and June 2018.

Table 1 - Comparison of demographics among scabies cases during the outbreak and non-outbreak months in Makkah, Saudi Arabia.

\begin{tabular}{|c|c|c|c|c|c|}
\hline \multicolumn{6}{|c|}{ Outbreak months } \\
\hline $\begin{array}{l}\text { Demographic and basic } \\
\text { characteristics }\end{array}$ & $\begin{array}{c}\text { March/April } \\
2018 \\
(n=78)\end{array}$ & $\begin{array}{l}\text { Others } \\
(n=274)\end{array}$ & OR & $95 \% \mathrm{CI}$ & $(P$-value $)$ \\
\hline \multicolumn{6}{|l|}{ Gender } \\
\hline Male & $28(35.9)$ & $115(42.0)$ & & & \multirow{3}{*}{$(0.336)$} \\
\hline Female & & $159(58.0)$ & 1.3 & $(0.77,2.17)$ & \\
\hline Nationality & $50(64.1)$ & & & & \\
\hline Non-Saudi & $6(7.7)$ & $47(17.2)$ & & & \multirow[t]{2}{*}{$(0.045)$} \\
\hline Saudi & $72(92.3)$ & $227(82.8)$ & 2.5 & $(1.02,6.05)$ & \\
\hline Age - mean(SD) & $34.2(22.5)$ & $\begin{array}{r}39.7 \\
(24.0)\end{array}$ & 1.0 & $(0.98,1.00)$ & $(0.072)$ \\
\hline Body mass index - mean (SD) & $25.5(8.9)$ & $27.1(7.9)$ & 1.0 & $(0.94,1.01)$ & $(0.124)$ \\
\hline
\end{tabular}


actual number was 68 , while the maximum expected was 24 cases per month). Similarly, the number of cases in May was 1.5 times the expected maximum (the actual number was 36, while the expected maximum was 24 cases per month). Such significant increase in the expected number of cases was considered an outbreak.

During the outbreak, the age, gender, and body mass index (BMI) of patients did not differ significantly from before the outbreak (Table 1). Females constituted the vast majority of the patients before $(58 \%)$ and during (58\%) the outbreak ( $p=0.336)$. The mean age of patients was $39.7 \pm 24.0$ years before the outbreak and $34.2 \pm 28.5$ years during the outbreak $(p=0.072)$. The BMI of patients was $27.1 \pm 7.9$ before the outbreak and $25.5 \pm 8.9$ during the outbreak $(p=0.124)$. There were no statistically significant differences in these socio-demographic variables between the 2 studied groups $(p>0.05)$. However, the OR for Saudi nationals to non-Saudis during the outbreak were 2.5 times higher during the outbreak period compared to before the outbreak (95\%CI:1.02, 6.05). Saudi patients constituted $92.3 \%$ of scabies patients during the outbreak and $82.2 \%$ of patients before the outbreak $(p=0.045)$ (Table 1).

To analyze the factors associated with the sudden increase in the number of reported scabies cases, the comorbidities and the risk factors for scabies were compared between the patients reported before the outbreak months and those reported during the outbreak (Tables 2 and 3). The comorbidities identified during the study are shown in Table 2 . There were no statistically significant differences between the 2 groups with regards to these comorbidities. By contrast, it was noted that the risk of scabies was significantly higher among patients with additional risk factors $(25.8 \%$ versus $8.2 \%, p=0.014)$ before the outbreak than during the outbreak (Table 3). In particular, patients with catheterization ( $15.9 \%$ versus $1.9 \%, p=0.023)$, bedridden $(25.8 \%$ versus $8.2 \%, p=0.014)$, obese (37.2\% versus $24.4 \%, p=0.036)$, and pregnant women (34.3\% versus $16.7 \%, p=0.004$ ) were at higher risk of scabies before the outbreak months than during the outbreak (Table 3).

Regarding the clinical characteristics and pattern of scabies, it was noted that the main clinical presentation of scabies before $(72.1 \%)$ and during $(61.9 \%)$ the outbreaks was pruritus during the outbreaks and before the outbreaks ( $p=0.157)$. The main site affected during the outbreaks was hands $(64.8 \%)$, while the main site affected prior to the outbreaks was the upper arm and axilla (68.7\%) (Table 4). Comparative analysis
Table 2 - Comparison of comorbidities among scabies cases during the outbreak and non-outbreak months in Makkah, Saudi Arabia.

\begin{tabular}{|c|c|c|c|c|c|}
\hline \multirow[t]{2}{*}{ Variables } & \multicolumn{2}{|c|}{$\begin{array}{c}\text { Outbreak } \\
\text { n (\%) }\end{array}$} & \multirow[t]{2}{*}{ OR } & \multirow[t]{2}{*}{$95 \% \mathrm{CI}$} & \multirow[t]{2}{*}{$P$-value } \\
\hline & $\begin{array}{c}\text { Yes } \\
(\mathrm{n}=78)\end{array}$ & $\begin{array}{c}\text { No } \\
(\mathbf{n}=274)\end{array}$ & & & \\
\hline \multicolumn{6}{|c|}{ Comorbidity } \\
\hline No & $33(42.3)$ & $95(34.7)$ & & & \multirow{2}{*}{0.217} \\
\hline Yes & $45(57.7)$ & $179(65.3)$ & 0.7 & $0.43-1.21$ & \\
\hline \multicolumn{6}{|c|}{ History diabetes mellitus } \\
\hline No & $63(80.8)$ & $211(77.0)$ & & & \multirow[t]{2}{*}{0.481} \\
\hline Yes & $15(19.2)$ & $63(23.0)$ & 0.8 & $0.42-1.5$ & \\
\hline \multicolumn{6}{|c|}{ History hypertension } \\
\hline No & $66(84.6)$ & $208(75.9)$ & & & \multirow[t]{2}{*}{0.106} \\
\hline Yes & $12(15.4)$ & $66(24.1)$ & 0.6 & $0.29-1.12$ & \\
\hline \multicolumn{6}{|c|}{ History renal disease } \\
\hline No & 70 (89.7) & $247(90.1)$ & & & \multirow[t]{2}{*}{0.917} \\
\hline Yes & $8(10.3)$ & $27(9.9)$ & 1.1 & $0.45-2.4$ & \\
\hline \multicolumn{6}{|c|}{ History cancer } \\
\hline No & $76(97.4)$ & $248(90.5)$ & & & \multirow[t]{2}{*}{0.064} \\
\hline Yes & $2(2.6)$ & $26(9.5)$ & 0.3 & $0.06-1.08$ & \\
\hline \multicolumn{6}{|c|}{ History hepatic disease } \\
\hline No & $76(97.4)$ & $265(96.7)$ & & & \multirow[t]{2}{*}{0.748} \\
\hline Yes & $2(2.6)$ & $9(3.3)$ & 0.8 & $0.16-3.66$ & \\
\hline \multicolumn{6}{|c|}{ History COPD } \\
\hline No & $68(87.2)$ & $244(89.1)$ & & & \multirow[t]{2}{*}{0.646} \\
\hline Yes & $10(12.8)$ & $30(10.9)$ & 1.2 & $0.56-2.57$ & \\
\hline \multicolumn{5}{|c|}{ History autoimmune disease } & \multirow{3}{*}{0.907} \\
\hline No & $77(98.7)$ & $270(98.5)$ & & & \\
\hline Yes & $1(1.3)$ & $4(1.5)$ & 0.9 & $0.1-7.96$ & \\
\hline \multicolumn{6}{|c|}{ Dyslipidaemia } \\
\hline No & $62(79.5)$ & $237(86.5)$ & & & \multirow[t]{2}{*}{0.129} \\
\hline Yes & $16(20.5)$ & $37(13.5)$ & 1.7 & $0.86-3.17$ & \\
\hline \multicolumn{6}{|c|}{ Psychiatric disorder } \\
\hline No & $75(96.2)$ & $265(96.7)$ & & & 0.810 \\
\hline Yes & $3(3.8)$ & $9(3.3)$ & 1.2 & $0.31-4.46$ & \\
\hline Developn & lelay & & & & \\
\hline No & $77(98.7)$ & $271(98.9)$ & & & 0.891 \\
\hline Yes & $1 \quad(1.3)$ & $3(1.1)$ & 1.2 & $0.12-11.44$ & \\
\hline Hypothy & & & & & \\
\hline No & $75(96.2)$ & $261(95.3)$ & & & 0.737 \\
\hline Yes & $3(3.8)$ & $13(4.7)$ & 0.8 & $0.22-2.89$ & \\
\hline Cardiova & disease & & & & \\
\hline No & $76(97.4)$ & $252(92.0)$ & & & 0.110 \\
\hline Yes & $2(2.6)$ & $22(8.0)$ & 0.3 & $0.07-1.31$ & \\
\hline Historyo & & & & & \\
\hline No & $48(61.5)$ & $161(58.8)$ & & & 0.659 \\
\hline Yes & $30(38.5)$ & $113(41.2)$ & 0.9 & $0.53-1.49$ & \\
\hline
\end{tabular}

demonstrated that symptoms involving upper arms, axillae, and torso were significantly under-represented among outbreak patients. Upper arms and axillary affection occurred in $35.7 \%$ during the outbreak and $68.7 \%$ of patients before the outbreaks ( $p=0.048$ ), and the torso was affected in $50 \%$ and $66.4 \%$ of the patients in the 2 groups, respectively $(p=0.33)$. Otherwise, the clinical presentation among outbreak patients was similar to other patients who had scabies before the outbreak (Table 4). Additionally, despite the increased 
Table 3 - Comparison of risk factors among scabies cases during the outbreak and non-outbreak months in Makkah, Saudi Arabia.

\begin{tabular}{|c|c|c|c|c|c|c|}
\hline \multirow[t]{2}{*}{ Risk of scabies } & & \multicolumn{2}{|c|}{ Outbreak n (\%) } & \multirow[t]{2}{*}{ OR } & \multirow[t]{2}{*}{$95 \% \mathrm{CI}$} & \multirow[t]{2}{*}{$P$-value } \\
\hline & & Yes $(\mathrm{n}=78)$ & No $(n=274)$ & & & \\
\hline \multirow{2}{*}{ Presence of risk factors } & No & $36(46.2)$ & $85(31.0)$ & & & 0.014 \\
\hline & Yes & $42(53.8)$ & $189(69.0)$ & 0.5 & $0.31-0.88$ & \\
\hline \multirow[t]{2}{*}{ Affected family member } & No & $37(62.7)$ & $61(58.1)$ & & & 0.563 \\
\hline & Yes & $22(37.3)$ & $44(41.9)$ & 0.8 & $0.43-1.59$ & \\
\hline \multirow[t]{2}{*}{ Affected school/work colleague } & No & $44(93.6)$ & $77(98.7)$ & & & 0.156 \\
\hline & Yes & $3(6.4)$ & $1 \quad(1.3)$ & 5.3 & $0.53-52.01$ & \\
\hline \multirow[t]{2}{*}{ Hygiene } & No & $36(87.8)$ & $127(93.4)$ & & & 0.253 \\
\hline & Yes & $5(12.2)$ & $9 \quad(6.6)$ & 2.0 & $0.62-6.22$ & \\
\hline \multirow[t]{2}{*}{ Low immune status } & No & $34(91.9)$ & $112(91.8)$ & & & 0.986 \\
\hline & Yes & $3(8.1)$ & $10 \quad(8.2)$ & 1.0 & $0.26-3.8$ & \\
\hline \multirow[t]{2}{*}{ Bedridden } & No & $45(91.8)$ & $118(74.2)$ & & & 0.014 \\
\hline & Yes & $4 \quad(8.2)$ & $41(25.8)$ & 0.3 & $0.09-0.76$ & \\
\hline \multirow[t]{2}{*}{ Pre-diagnosed with venereal disease } & No & $64(97.0)$ & $190(99.5)$ & & & 0.149 \\
\hline & Yes & $2(3.0)$ & $1 \quad(0.5)$ & 5.9 & $0.53-66.58$ & \\
\hline \multirow[t]{2}{*}{ Dementia } & No & $69(100)$ & $188(97.9)$ & & & - \\
\hline & Yes & 0 & $4(2.1)$ & - & - & \\
\hline \multirow[t]{2}{*}{ Catheterization } & No & $51(98.1)$ & $148(84.1)$ & & & 0.028 \\
\hline & Yes & 1 (1.9) & $28(15.9)$ & 0.1 & $0.01-0.78$ & \\
\hline \multirow[t]{2}{*}{ Obesity } & No & $59(75.6)$ & $172(62.8)$ & & & 0.036 \\
\hline & Yes & $19(24.4)$ & $102(37.2)$ & 0.5 & $0.31-0.96$ & \\
\hline \multirow[t]{2}{*}{ Pregnancy } & No & $65(83.3)$ & $180(65.7)$ & & & 0.004 \\
\hline & Yes & 13 (16.7) & $94(34.3)$ & 0.4 & $0.2-0.73$ & \\
\hline Malnutrition & No & $78(100)$ & $274(100)$ & - & - & - \\
\hline Paralysis & No & $76(97.4)$ & $269(98.2)$ & & & 0.681 \\
\hline
\end{tabular}

Table 4 - Comparison of risk factors among scabies cases during the outbreak and non-outbreak months in Makkah, Saudi Arabia.

\begin{tabular}{lcrcc}
\hline $\begin{array}{l}\text { Signs and } \\
\text { symptoms }\end{array}$ & \multicolumn{2}{c}{ Outbreak } & \multicolumn{2}{c}{ Comparison } \\
& Yes & No & Test & $P$-value \\
\hline Pruritus & $44(72.1)$ & $104(61.9)$ & 2.0 & 0.152 \\
Rash & $22(36.1)$ & $51(30.5)$ & 0.6 & 0.428 \\
Papules & $18(29.5)$ & $54(32.3)$ & 0.2 & 0.684 \\
Breasts & $12(28.6)$ & $24(25.5)$ & 0.1 & 0.710 \\
Face/scalp/neck & $13(24.1)$ & $56(37.8)$ & 3.3 & 0.068 \\
Excoriations & $3(4.9)$ & $18(10.8)$ & 1.8 & 0.176 \\
Plaques & $3(4.9)$ & $4(2.4)$ & FET & 0.388 \\
Burrows & $2(3.3)$ & $6(3.6)$ & FET & 1.000 \\
Eruptions & $2(3.3)$ & & - & - \\
Crustations/scales & $1(1.6)$ & $6(3.6)$ & - & - \\
Hands & $35(64.8)$ & $90(60.0)$ & 0.4 & 0.533 \\
Upper arms/axillae & $29(53.7)$ & $103(68.7)$ & 3.9 & 0.048 \\
Lower arms/wrists & $29(53.7)$ & $93(62.0)$ & 1.1 & 0.286 \\
Upper legs/knees & $29(53.7)$ & $90(60.0)$ & 0.6 & 0.421 \\
Torso & $27(50.0)$ & $99(66.4)$ & 4.6 & 0.033 \\
Lower legs/ankles & $27(50.0)$ & $84(56.0)$ & 0.6 & 0.448 \\
Buttocks/genitalia/ & $23(42.6)$ & $84(56.0)$ & 2.9 & 0.091 \\
groin & & & & \\
\hline$*$ * & & &
\end{tabular}

*Due to a small sample size, no statistical comparison was conducted. FET - Fisher's exact test
Table 5 - Comparison of treatments among scabies cases during the outbreak and non-outbreak months in Makkah, Saudi Arabia.

\begin{tabular}{lrrrr}
\hline \multirow{2}{*}{ Treatment type } & \multicolumn{2}{c}{ Outbreak } & \multicolumn{2}{c}{ Comparison } \\
& \multicolumn{1}{c}{ Yes } & No & $x^{2}$ & $P$-value \\
\hline Permethrin & $56(75.7)$ & $112(41.0)$ & & \\
Crotamiton & $10(13.5)$ & $131(48.0)$ & & \\
$\begin{array}{l}\text { Permethrin and } \\
\text { crotamiton }\end{array}$ & $8(10.8)$ & $28(10.3)$ & 30.0 & $<0.001$ \\
$\begin{array}{l}\text { Ivermectin } \\
\text { Admission }\end{array}$ & 0 & $2(0.7)$ & & \\
$\quad$ No & $75(96.2)$ & $237(86.5)$ & & \\
$\quad$ Yes & $3(3.8)$ & $37(13.5)$ & 5.6 & 0.018 \\
\hline
\end{tabular}

number of cases during the outbreak, the severity of the disease did not increase, as suggested by the significantly decreased admission rate during the outbreak $(3.8 \%$ compared to $13.5 \%$ ) (Table 5).

Upon studying the treatment modalities, the results from this study revealed that the pattern of treatment differed significantly during the Makkah outbreak. Specifically, Permethrin prescriptions increased $(75.6 \%$ versus $41.0 \%)$ and Crotamiton prescriptions decreased $(13.5 \%$ versus $48 \%)(p<0.001)$. Also, Ivermectin was seldom used during the outbreaks. 
Discussion. The main aims of this study were to determine the rate of scabies cases reported from June 2016 to June 2018 in the KAMC in Saudi Arabia, and to analyze the risk factors associated with the sudden increase in the number of reported cases. Moreover, it also aimed to provide a description of the clinical characteristics and pattern of the disease, as well as the treatment modalities used during and before the outbreaks. The results of the study have revealed that there was a significant increase in the number of cases reported to the KAMC and its primary centers during the months of March, April, May, and June 2018. Overall, 352 patients were diagnosed with scabies during the studied period. The number of cases increased by 2.8 times the maximum expected number per month in April and 1.5 times the maximum expected number in May.

The mean age of the recruited patients was 34.2 years during the outbreak and 39.7 years prior to the outbreak, and there was no significant difference between the genders. In disagreement with these results, the most commonly affected age groups reported in the Middle East region include preschool children, adolescents, and the elderly, with the least frequently reported group being patients in mid-adulthood.5,12 This difference may be attributed to the different social circumstances in Saudi Arabia and the presence of the Hajj or Omrah season in Makkah, which attracts more adults than children from different countries. The occurrence rates for different genders is a controversial topic in the literature; recent studies suggest that the occurrence rates are likely equal between gender groups and differences in prevalence are most likely attributable to the presence of other confounding factors. ${ }^{5}$

One of the primary objectives of this study was to explore the possible causes or risk factors that resulted in such a sudden increase in the number of scabies cases reported during the period between March and June 2018. To achieve this objective, a comparative analysis was carried out with regards to the patients' comorbidities and risk factors before and during the outbreaks to determine whether the outbreak could be attributed to particular risk factors or comorbidities. The results of the study have revealed that Saudi patients were 2.5 times more likely to be affected than non-Saudi patients during the outbreak in comparison to before the outbreak (CI:95\%, 1.02. 6.05, $p=0.045$ ). Thus, the increased number of cases observed during the outbreak months was not a result of increased infection in minority populations (non-Saudi nationals). Regarding the risk factors and comorbidities associated with scabies, various studies have reported that scabies was significantly predominant among immunocompromized patients, those with diabetes mellitus, advanced renal or hepatic disease, cancer, chronic obstructive pulmonary disease, dementia, immune-mediated diseases, those with an affected family member or work colleague, and those who were paralyzed, bedridden, catheterized, malnourished, or pregnant. ${ }^{13-22}$ Of particular interest, a recent study conducted in Taiwan emphasized the significantly high risk associated with catherization and immobilized states in the acquisition of scabies infection. ${ }^{6}$ Makigami et $\mathrm{al}^{23}$ in a study of 148 scabies patients, reported that certain risk factors, namely dementia, psychiatric and behavioral disturbances, low lymphocytic count, and impaired immunity were associated with an increased risk of scabies infection and recurrence. These comorbidities and risk factors, when compared between patients recruited to the present study during and before the outbreak, were not significantly different $(p>0.05)$. Although cases before the outbreak were more likely to have additional risk factors, such as being bedridden, catheterization, obesity, and pregnancy $(p<0.05)$, the increase in the number of cases during the outbreak affected relatively healthy individuals in the community, suggesting that poor education, rather than an increased infection in high-risk patients, led to the increased number of cases in the community.

In April 2018, after the scabies outbreak in Makkah, the Ministry of National Guard Health Affairs and the Ministry of Health in Saudi Arabia adopted preventive measures to prevent scabies. These measures included appropriate health education of the local and general community as well as the healthcare providers about the scabies disease, its risk factors and prevention strategies, isolation of infected individuals, proper hygiene, treatment methods, and the provision of sanitary tools for the public. ${ }^{24}$ Despite the significance of the adopted measures, the results of the present study have highlighted the importance of a special focus on adopting strategies related to community infection control and prevention.

After reviewing and comparing the clinical characteristics and pattern of the disease before and during the outbreak, the results showed that the clinical presentation of the disease was the same. However, symptoms involving the upper arms, axillae, and torso were significantly under-represented among outbreak patients. This could suggest that diagnosis during the outbreak may have been picked up early, before generalization of the rash, with possible reduced severity 
as indicated by the lower admission rates noted in the results. The variation in distribution of the rash may also have been a result of the communicable mode of transmission during the outbreak, further highlighting the importance of increasing community awareness as a primary preventive measure.

The pattern of treatment differed significantly during the Makkah outbreak. Permethrin prescriptions increased, while crotamiton prescriptions decreased significantly at this time. This change in treatment pattern may be attributed to the education or training efforts that were implemented to standardize the care offered by healthcare providers, as well as to the superior efficacy of permethrin in comparison to crotamiton in the treatment of scabies, particularly during an outbreak..$^{25-27}$ The time series analysis carried out in this study revealed that the duration of the studied outbreak was short. This may reflect the improved healthcare provider and community education, which likely resulted in good infection control. An improvement in healthcare provider education is suggested by the pattern of optimal therapy prescription during the outbreak. Based on the above, to prevent recurrence, we recommend the adoption of standard guidelines for case management, raising community awareness, and educating primary healthcare providers.

Study limitation. Results was presented from a single institution in Makkah region, and the results cannot be generalized. Nevertheless, this research provides data about the clinical presentation and risk factors in Saudi Arabia. This can provide a basis for future researchers to implement and evaluate preventive measures to reduce and recognize early cases of scabies in the province.

In conclusion, Saudi Arabia witnessed an outbreak of scabies during the period March to June 2018. The clinical presentation and risk factors for scabies were significantly different during the outbreak months. The outbreak duration was short, indicating that adequate management was adopted in Saudi hospitals. The results of the present study have highlighted the importance of a special focus on adopting strategies related to community infection control and prevention.

\section{References}

1. Gunning K, Pippitt K, Kiraly B, Sayler M. Pediculosis and scabies: treatment update. Am Fam Physician 2012; 86: 535-541.

2. Strong M, Johnstone PW. Interventions for treating scabies. Cochrane Database Syst Rev 2007: CD000320.

3. Fathy FM, El-Kasah F, El-Ahwal AM. Clinical and parasitological study on scabies in Sirte, Libya. J Egypt Soc Parasitol 2010; 40: 707-731.
4. Chung SD, Lin HC, Wang KH. Increased risk of pemphigoid following scabies: a population-based matched-cohort study. $J$ Eur Acad Dermatology Venereol 2014; 28: 558-564.

5. Hay RJ, Steer AC, Engelman D, Walton S. Scabies in the developing world-its prevalence, complications, and management. Clin Microbiol Infect 2012; 18: 313-323.

6. Wang CH, Lee SC, Huang SS, Kao YC, See LC, Yang SH. Risk factors for scabies in Taiwan. J Microbiol Immunol Infect 2012; 45: 276-280.

7. Fuller LC. Epidemiology of scabies. Curr Opin Infect Dis 2013; 26: 123-126.

8. Thornley S, Marshall R, Jarrett P, Sundborn G, Reynolds E, Schofield G. Scabies is strongly associated with acute rheumatic fever in a cohort study of Auckland children. J Paediatr Child Health 2018; 54: 625-632.

9. Walton SF, Currie BJ. Problems in diagnosing scabies, a global disease in human and animal populations. Clin Microbiol Rev 2007; 20: 268-279.

10. Amin T, Ali A, Kaliyadan F. Skin disorders among male primary school children in Al Hassa, Saudi Arabia: prevalence and socio-demographic correlates - a comparison of urban and rural population. Rural Remote Health 2011; 11: 1517.

11. The Gulf Daily News online desk. 1038 cases of scabies diagnosed in Mecca. [Updated 2018. Cited 2018 December 14th]. Available from: http://www.gdnonline.com/ Details/345923/1038-cases-of-scabies-diagnosed-in-Mecca

12. Mimouni D, Ankol OE, Davidovitch N, Gdalevich M, Zangvil E, Grotto I. Seasonality trends of scabies in a young adult population: A 20-year follow-up. Br J Dermatol 2003; 149: 157-159

13. Roberts LJ, Huffam SE, Walton SF, Currie BJ. Crusted scabies: Clinical and immunological findings in seventy-eight patients and a review of the literature. J Infect 2005; 50: 375-381.

14. Romani L, Koroivueta J, Steer AC, Kama M, Kaldor JM, Wand $\mathrm{H}$, et al. Scabies and impetigo prevalence and risk factors in fiji: A national survey. PLoS Negl Trop Dis 2015; 9: e0003452.

15. Bouvresse S, Chosidow O. Scabies in healthcare settings. Curr Opin Infect Dis 2010; 23: 111-118.

16. Raza N, Qadir SNR, Agha H. Risk factors for scabies among male soldiers in Pakistan: Case-control study. East Mediterr Heal J 2009; 15: 1105-1110.

17. Makigami K, Ohtaki N, Ishii N, Yasumura S. Risk factors of scabies in psychiatric and long-term care hospitals: A nationwide mail-in survey in Japan. J Dermatol 2009; 36: 491-498.

18. Mahé A, Libreville G, Hay RJ. Epidemiology and management of common skin diseases in children in developing countries. Geneva (CH): World Health Organization; 2005.

19. Hegab DS, Kato AM, Kabbash IA, Dabish GM. Scabies among primary schoolchildren in Egypt: Sociomedical environmental study in Kafr El-Sheikh administrative area. Clin Cosmet Investig Dermatol 2015; 8: 105-011.

20. Buehlmann M, Beltraminelli H, Strub C, Bircher A, Jordan X, Battegay M, et al. Scabies Outbreak in an intensive care unit with 1,659 exposed individuals-key factors for controlling the outbreak. Infect Control Hosp Epidemiol 2009; 30: 354-360.

21. Tsutsumi M, Nishiura H, Kobayashi T. Dementia-specific risks of scabies: Retrospective epidemiologic analysis of an unveiled nosocomial outbreak in Japan from 1989-90. BMC Infect Dis 2005; 5: 85 . 
22. Feldmeier H, Jackson A, Ariza L, Lins Calheiros CM, de Lima Soares V, Oliveira FA, et al. The epidemiology of scabies in an impoverished community in rural Brazil: Presence and severity of disease are associated with poor living conditions and illiteracy. J Am Acad Dermatol 2009; 60: 436-443.

23. Makigami K, Ohtaki N, Ishii N, Tamashiro T, Yoshida S, Yasumura S. Risk factors for recurrence of scabies: A retrospective study of scabies patients in a long-term care hospital. J Dermatol 2011; 38: 874-879.

24. Ministry of Health. MOH News - Statement of clarification on scabies and how to handle reported cases in Makka. 2018 [Updated 2019. Cited 2018 December 14th]. Available from: https://www.moh.gov.sa/en/Ministry/MediaCenter/News/ Pages/news-2018-04-03-006.aspx
25. Dressler C, Rosumeck S, Sunderkötter C, Werner RN, Nast A. Originalarbeit: Therapie der Skabies: Systematische literaturübersicht von randomisierten kontrollierten studien. Dtsch Arztebl Int 2016; 113: 757-762.

26. Goldust M, Rezaee E, Raghiafar R. Topical ivermectin versus crotamiton cream $10 \%$ for the treatment of scabies. Int J Dermatol 2014; 53: 904-908.

27. Mila-Kierzenkowska C, Woźniak A, Krzyzyńska-Malinowska E, Kałuzna L, Wesołowski R, Poćwiardowski W, et al. Comparative efficacy of topical pertmehrin, crotamiton and sulfur ointment in treatment of scabies. J Arthropod Borne Dis 2017; 11:1-9.

\section{Illustrations, Figures, Photographs}

All figures or photographs should be submitted in a high resolution (minimum 300 DPI) electronic version saved in jpeg or tiff format. Original hard copies of all figures may be requested when necessary. Photographs will be accepted at the discretion of the Editorial Board. All lettering, arrows, or other artwork must be done by an artist or draftsman. If arrows are used please ensure they appear in a different color to the background color, preferably black with a white border, or white with a black border. If arrows distinguish different items on the figure then different arrow styles should be used ie. long, short, wide, narrow. Written informed consent for publication must accompany any photograph in which the subject can be identified. Written copyright permission, from the publishers, must accompany any illustration that has been previously published. 